\title{
Prevalence and associated factors of Female genital mutilation among reproductive age women's of Damot Gale woreda, Wolaita Zone, Southern Ethiopia: a cross-sectional study, 2018
}

Bargude Balta Anjulo ( $\sim$ barjuda@gmail.com )

Hawassa University

Amanuel Fanta Lambebo

Hawassa college of health science

\section{Research Article}

Keywords: female genital mutilation, clitoridoctomy, Ethiopia

Posted Date: September 24th, 2021

DOl: https://doi.org/10.21203/rs.3.rs-885197/v1

License: (c) (1) This work is licensed under a Creative Commons Attribution 4.0 International License. Read Full License 


\section{Abstract}

Background: Female genital mutilation (FGM) is estimated to have been practiced on at least 200 million girls and women in 30 countries around the world. Clitoridoctomy is the most common type of FGM in Ethiopia.

Objectives: The aim of the study was to assess the magnitude of Female Genital Mutilation and associated factors among women's in Damot Gale Woreda of Wolayita zone.

Methods: A quantitative community-based cross-sectional study was used. Face-to-face interviews with prepared questionnaires were used to collect data. SPSS version 20 software was used to analyze the data. The prevalence of FGM was determined using descriptive statistics. The researchers utilized a bivariate and multivariate logistic regression model to find independent determinants of FGM.

Result: 296 women were circumcised out of a total of 333, indicating that FGM is prevalent in the research area (88.9\%). Mother education (AOR: 0.454, 95\% Cl: 0.209-0.984), age (AOR-1.86, 95\% Cl: $0.42-$ $0.98)$ ), knowledge that FGM causes health problems (AOR: $0.356,95 \% \mathrm{Cl}: 0.145-0.877$ ), and support for tradition (AOR: $14.595,95 \%$ Cl: 3.391-6.807) were all independently linked to FGM.

Conclusion: Prevalence of FGM was associated with age, education, Knowledge of health problems and Tradition.

\section{Introduction}

Female genital mutilation (FGM) is defined by the World Health Organization as any procedure that involves partial or entire removal of the external female genitalia, or other harm to the female genital organs for no medical reason. The practice is usually carried out by women who are often involved in other important aspects of their communities, such as attending childbirths. Health care providers, on the other hand, execute more than 18 percent of all FGM, and the tendency toward medicalization is growing. (WHO fact sheet, 2019). At least 200 million girls and women worldwide have been subjected to female genital mutilation (FGM) in 30 countries, including Ethiopia, Kenya, Somalia, Tanzania, and Uganda. They are also becoming more common in Europe, Australia, New Zealand, Canada, and the United States, mostly among immigrants from cultures where female genital mutilation (FGM) is a common practice(UNFPA-UNICEF, 2019).

Out of a total population of 205683 girls aged 0-18 originating from countries where female genital mutilation is prevalent, it is estimated that 12 to $21 \%$ of girls in France are at danger of female genital mutilation.(European Institute for Gender Equality, 2018). Teixeira and Lisboa calculated that nearly 6,500 immigrant women 15 years and older had been circumcised in Portugal, while 1,830 girls under 15 years are likely to or have been circumcised, according to the study Odukogbe et al. 2016 report.(Odukogbe et al., 2017). The practice is founded in traditional beliefs, values, and attitudes, and is regarded as a rite of passage into femininity and child marriage in many nations (WHO, 2016). 
FGM/C is prevalent in more than $70 \%$ of African countries, according to estimates from Burkina Faso, Djibouti, Egypt, Eritrea, Ethiopia, Guinea, Mali, Mauritania, Northern Sudan, and Somalia. However, because of ethnicity and culture, there is a wide range of frequency between and within countries. Mali, for example, has a frequency of 92 percent, compared to 28 percent in Senegal. The most severe form of FGM (infibulations), which involves the sewing and narrowing of the vaginal hole, is estimated to have been performed on $15 \%$ of all circumcised women. However, in Djibouti, Somalia, and Sudan, this method of circumcision accounts for about $80 \%-90 \%$ of all circumcisions(The European Institute for Gender Equality, 2015).

FGM is a type of gender-based violence that has been identified as a harmful practice and a violation of girls' and women's human rights. In the 28 African nations and Yemen where FGM is performed, over 125 million girls and women have had FGM, and 3 million girls are projected to be at danger of FGM each year(UNICEF, 2013b). According to an Ethiopian demographic and health survey, 65 percent of women between the ages of 15 and 49 are circumcised.

Clitoridoctomy is the most common kind of FGM in Ethiopia. Without having their vaginal area sowed, 96.2 percent of women and 96.5 percent of daughters have undergone some sort of circumcision. Infibulations is the most extreme type of FGM/C, involving the excision of genitalia and the closing of the vaginal hole with stitching. It has been experienced by 2.9 percent of Ethiopian women and 3.4 percent of daughters. This is concerning because it suggests that some women who have never had infibulations want to have their daughters circumcised in the most severe way possible. Ethiopia has one of the highest rates of infant girls who are subjected to any type of female genital mutilation(UNICEF, 2013b).

The study's goal was to determine the prevalence of female genital mutilation in the study area, as well as the factors that contribute to the continuation of female genital mutilation.

\section{Methods}

\section{Study area and Period}

The research was carried out in Damot Gale Woreda, in the Wolayita zone of Southern Ethiopia. Damote Gale was around 302 kilometers south of Addis Ababa, through Butajira's major road, and 138 kilometers from Hawassa. There are 30 rural kebeles in the woreda. The population of Damot gale Woreda was estimated to be 154,610 in the 2008 E.C census (Damot Gale Wored Static bureau, 2008). The research was carried out between the months of June and August. Area map of Damot Gale was shown in the figure 1.

\section{Research Design}


A community-based analytic cross-sectional quantitative design was conducted at Damot Gale Woreda, Wolayita Zone.

\section{Source Population}

\section{Women residing in Damote Gala Woreda served as the source population.}

\section{Study population}

The study population was drawn from all reproductive age (18-49) women in study area.

\section{Sample Size Determination}

The investigation Woreda Damot Gale was chosen on purpose because FGM is a widely performed area. Then, at random, eight rural Kebeles from the Woreda's 30 Kebles were chosen. The sample size was then proportionally allocated to each of the selected Kebles based on the number of homes in each. The computed sample size was then proportionally allocated to each of the eight Kebeles based on the number of households in each Keble. Finally, the Keble lottery method was used to choose study subjects using family folder numbers. Women from chosen families were eligible to participate in the interview as respondents. The sample size was calculated using a single population proportion formula. According to the EDHS, the current prevalence of FGM in Southern Ethiopia was 62 percent (Demographic and health survey, 2016).

$d=$ Margin of error $5 \%$

$n=(z a / 2)^{2} P(1-P) / d^{2}$

$\mathrm{n}=[1.96 * 1.96] 0.62[1-0.62] / 0.05^{\star} 0.05$

$\mathrm{n}=315$ then add $10 \%$ non-response rate gives

Final sample size is 347 respondents.

\section{- Z=1.96 at desired confidence level 95\%}

$-10 \%$ of non-response rate

\section{Data Collection Procedures}

Data was obtained by face-to-face interviews using prepared questionnaires after a two-day training for four female nurses with at least a diploma. The majority of the training included the goal of the study, 
each portion of the questionnaire, consents, the right to participate or not participate, the ability to withdraw at any moment, confidentiality, and how to approach the study. The data collection method was overseen by two trained supervisors and the primary investigator at each step daily to assure data quality. The data was gathered between March 1 and March 15, 2018.

The primary data sources were responses from married women aged 18 to 49 who were interviewed in their homes. To ensure that the data was of good quality, the following actions were done. The surveys were composed entirely in English. A fifth of the sample size was pre-tested for the questionnaire in another woreda near Damot gale. Woreda (sodo zuriya) was done prior to data collection, and equipment changes were made as appropriate. On a daily basis, the supervisors and the lead investigator checked the data for completeness, clarity, and consistency. The total activity was overseen by the principal investigator, who was also in charge of data collection. Finally, data was double-entered into Epi-data 3.1 program for verification.

\section{Data Analysis}

At the end of each data collection day, the collected data was reviewed for completeness and consistency. It was also cleaned, edited, coded, and entered into Epi data program version 3.1. The data is then exported to SPSS 20.0 for analysis. The frequency distribution and percentage of different variables were generated during the analysis phase to define and summarize the main socio-demographic chasm.

To give a fast overview of the variables, the results were presented in the form of frequency tables, pie charts, and graphs. To describe the prevalence of FGM in the Woreda study population in relation to pertinent variables, descriptive statistics such as frequencies, proportions, and summary statistics were utilized. To assess the relationship between different predictor factors and the dependent variable, researchers performed bivariate and multivariate analysis with logistic regression models.

A binary logistic regression analysis was used to evaluate the bivariate association between each independent variable and the outcome variable. For multivariate logistic regression, variables that exhibited a significant correlation on bivariate analysis with a p-value of 0.25 were employed. To reduce the impact of confounding variables and identify FGM factors, multivariate logistic regression analysis was employed. The adjusted odds ratio with 95 percent confidence interval and p-value 0.05 as cut point were used to analyze the strength of the link between dependent and independent variables.

\section{Ethical Consideration}

At initial Ethical review later was taken from Hawassa university school of Gender studies. Then the nature and purpose of the study were explained to the respondents and Woreda administration. Following ethical permission from the Damot Gale Woreda administrative office, the Woreda delivered an official letter to the sampled Kebeles and concerned offices. After all, verbal informed consent to participate in 
the study was gained from the respondents. The survey participants were given an open and honest explanation of the survey's goal, a description of the benefits, and the opportunity to ask any questions they had. They were also told that they might withdraw their agreement and quit participation at any time without fear of being labeled chauvinists. The privacy and confidentiality of the information acquired were ensured throughout the operation.

\section{Results}

\section{Socio-Demographic Characteristics of Respondents}

A total of 333 women took part in the survey, with a 96 percent response rate. Due to incompleteness, fourteen questionnaires (3.4\%) were rejected. Daughters in this study ranged in age from 18 to 49 years old. The average age was 34.05 years (SD 7.9). In terms of religious affiliation, 166 respondents (49.8\%) were Protestant, 111 (33.3\%) were Orthodox, and 42 (12.6\%) were Muslims. The ethnicity of almost all of the interviewees was Wolayita (270). (81.1 percent). In terms of education, 208 (62.5\%) of respondents were literate, while 125 (37.5\%) had no formal education. In terms of familial educational background, the vast majority of research participants were uneducated. Formal schooling was followed by $212(63.6 \%)$ and $121(36.4 \%)$. Husbands of respondents 143 (42.9 percent) had some level of education, while others had no formal education (Table 1).

Table 1: Socio-Demographic Characteristics of women's of Damot Gale Woreda, Wolayita Zone, Southern Ethiopia 2018. 


\begin{tabular}{|lll|}
\hline Variables & Frequency & Precentage \\
\hline Age of the respondents & 30 & 9 \\
Age 18-22 & 78 & 23.4 \\
Age $23-27$ & 95 & 28.5 \\
Age $28-32$ & 46 & 13.8 \\
Age 33-37 & 84 & 25.2 \\
Age >38 & & \\
\hline Religion of the respondent & 166 & 49.8 \\
Protestant & 111 & 33.3 \\
Orthodox & 42 & 12.6 \\
Muslim & 14 & 4.2 \\
Catholic & & \\
\hline Ethnicity of the respondent & 270 & 81.1 \\
Wolayita & 48 & 14.4 \\
Amhara & 143 & 4.5 \\
Oromo/kambata/Hadiya/Other & 15 & 63.5 \\
\hline Educational status of the respondent & & 37.5 \\
Illiterate & 208 & \\
Literate & 125 & \\
\hline Literacy status of the father & & \\
Literate & 190.3 \\
Illiterate & & \\
\hline Literacy status of the mother & & \\
Literate & & \\
Illiterate & & \\
\hline
\end{tabular}

The majority of the respondents (324, or 97.3 percent) were married, while some ( 8 , or 2.4 percent) were divorced, and one was widowed $(0.3 \%)$. Ninety-two percent $(57.7 \%)$ of fathers were farmers, whereas 151 percent (45\%) of moms worked as housewives. In terms of respondents' wealth, sixty-eight (20.4\%) were judged to be in the second quintal index level, while about the same proportion (19.8\%) were in the highest quintal index level. As a result, we concluded that the amount of wealth among respondents is not considerably different (Table 2). 
Table 2: Marital Status and Socio Economic Characteristics of women's of Damot Gale Woreda, Wolayita Zone, Southern Ethiopia 2018.

\begin{tabular}{|c|c|c|}
\hline Variables & Frequency & Precentage \\
\hline \multicolumn{3}{|c|}{ Marital status } \\
\hline Married & 324 & 97.3 \\
\hline Divorced & 8 & 2.4 \\
\hline Widowed & 1 & 0.3 \\
\hline \multicolumn{3}{|c|}{ Occupation of the Husband } \\
\hline Farmer & 192 & 57.7 \\
\hline Civil servant & 14 & 4.2 \\
\hline Merchant & 84 & 25.2 \\
\hline Other & 43 & 12.9 \\
\hline \multicolumn{3}{|c|}{ Occupation of the mother } \\
\hline Housewife & 151 & 45.5 \\
\hline Civil servant & 9 & 2.7 \\
\hline Farmer & 98 & 29.4 \\
\hline Merchant & 61 & 18.3 \\
\hline Other & 14 & 4.2 \\
\hline \multicolumn{3}{|c|}{ Wealth quintal } \\
\hline Lowest & 66 & 19.8 \\
\hline Second & 68 & 20.4 \\
\hline Middle & 66 & 19.8 \\
\hline Fourth & 67 & 20.1 \\
\hline Highest & 66 & 19.8 \\
\hline
\end{tabular}

Figure 2 depicts the frequency distribution of female genital mutilation in relation to respondents' educational status. Their educational background ranges from uneducated (no formal schooling) through grade twelve. In a nutshell, the graph showed that as educational levels rose, so did the prevalence of female genital mutilation (fig. 2).

Prevalence of the Female Genital Mutilation 
Two hundred and ninety-six (88.9\%) of the total responders were circumcised, whereas just thirty-seven $(11.1 \%)$ were not circumcised. The majority of circumcisions were done on children aged 1 to 5 , accounting for 171 circumcisions (51.4\%). Despite the fact that all types of circumcision were used in the studied area, Clitoridoctomy 286(85.8) is the most common kind of FGM. Traditional circumcisers 131 performed the majority of the circumcisions at home 282 (95.5\%). (39.3 percent). When asked who made the decision to circumcise their daughters, the majority decided by moms (182 (54.6\%), dads 139 (41.7\%), and $12(3.6 \%)$ by the daughter herself (Table 3 ).

Table 3: Characteristics of Women's Genital Mutilation of women's of Damot Gale Woreda, Wolayita Zone, Southern Ethiopia 2018. 


\begin{tabular}{|lll|}
\hline Variables & Frequency & Percentage \\
\hline Circumcision status & & \\
Circumcised & 296 & 88.9 \\
Uncircumcised & 37 & 11.1 \\
\hline Age at circumcision & & \\
1-5 & 171 & 51.4 \\
6-10 & 86 & 25.8 \\
11-15 & 34 & 10.2 \\
16-20 & 3 & 0.9 \\
$21-25$ & 1 & 0.3 \\
>25 & 1 & 0.3 \\
\hline Type of circumcision & & \\
Clitoridoctomy & 286 & 85.8 \\
Infibulations & 3 & 0.9 \\
Other & 7 & 2.1 \\
\hline Place of circumcision & & \\
At home & 282 & 95.5 \\
Private clinic & 3 & 0.6 \\
Other & 11 & 3.3 \\
\hline Decision power on FGM & & \\
Husband & 139 & \\
Wife & 182 & \\
Daughter & 11.3 \\
\hline
\end{tabular}

\section{Factor Associated with FGM}

Circumcision is regarded as a good tradition and typical practice by $154(46.2 \%)$ of the total respondents, whereas FGM is regarded as the best practice for the cleanliness of female genitals by $24(10.5 \%)$ of the 
total respondents. Eighty-one (24.3\%) of the women would like to continue circumcision because they believe it is a positive custom. When asked about their plan to circumcise their daughters, the majority of respondents (84 percent) said they would continue the practice.

In terms of FGM treatment, around $183(35.4 \%)$ and 66 (19.8\%) of women believe that legislation enforcement and women's access to education are the best approaches to prevent FGM, respectively, whereas only one $(0.3 \%)$ respondent believes that dads should take the effort to prevent FGM. Even though the vast majority of respondents $216(64.9 \%)$ are aware of the dangers of female genital mutilation, nearly half of them154 (46.2\%) confirm the practice's continuation because it is seen as a positive custom 81 (24.3\%). (Table4).

Table 4: Factors associated to FGM of women's of Damot Gale Woreda, Wolayita Zone, Southern Ethiopia 2018. 


\begin{tabular}{|c|c|c|}
\hline Variables & Frequency & Percentage \\
\hline \multicolumn{3}{|l|}{ FGM should continue } \\
\hline Yes & 154 & 46.2 \\
\hline No & 179 & 53.8 \\
\hline \multicolumn{3}{|l|}{ Main reasons FGM continued } \\
\hline Good tradition & 81 & 24.3 \\
\hline Cleanliness & 36 & 10.8 \\
\hline Reduction of female sexual hyper sensitivity & 10 & 3.0 \\
\hline Better marriage prospect & 16 & 4.8 \\
\hline To prevent female from early initiation of sex & 9 & 2.7 \\
\hline Prevention of virginity & 2 & 0.6 \\
\hline \multicolumn{3}{|l|}{ Participate FGM intervention activity } \\
\hline yes & 240 & 72.1 \\
\hline no & 93 & 27.9 \\
\hline \multicolumn{3}{|l|}{ Best way to stop FGM } \\
\hline Enforce legislation & 118 & 35.4 \\
\hline Sexual education & 37 & 11.1 \\
\hline Education to women & 66 & 19.8 \\
\hline Improve status of women & 22 & 6.6 \\
\hline Father responsibility & 1 & 0.3 \\
\hline \multicolumn{3}{|l|}{ Knew FGM cause health problems } \\
\hline Yes & 216 & 64.9 \\
\hline No & 117 & 35.1 \\
\hline \multicolumn{3}{|l|}{ Health Problems on circumcised women } \\
\hline During sexual intercourse & 85 & 28.7 \\
\hline During menstrual flow & 58 & 19.5 \\
\hline Obstructed labor & 73 & 24.6 \\
\hline Bleeding due to procedure & 74 & 25 \\
\hline Other & 6 & 2.2 \\
\hline
\end{tabular}




\section{Continue to circumcise daughters}

Yes

No
280

$53 \quad 15.9$

Regarding health complication out of those who face the complication of FGM $31.8 \%, 56.8 \%$ and $11.4 \%$ were went to health institution, traditional healer and other places to cure from the defect respectively (Fig. 3)

When females were asked if they had ever heard of Female Genital Mutilation, nearly two hundred ninetynine percent (89.8\%) said they had recently learned of FGM in the research region. While nearly ten percent of respondents had no access to information regarding FGM, 121 (36.3\%) acquire their knowledge via the radio. Furthermore, $250(75.1 \%)$ of women are aware of written laws against female genital mutilation. When asked about female genital circumcision and its impact on women's rights, the majority of respondents $(71.5 \%$ ) were unaware of the legal status of FGM, while just $28 \%$ of women believe circumcision violates women's human rights (Fig. 4).

Despite the fact that several measures to prevent FGM were carried out in the research area, the prevalence of FGM remains high due to insufficient law enforcement and community resistance (table 5). This is in line with a qualitative study in which the majority of focus group discussants stated that punishment was ineffective and that the community was resistive to anti-FGM efforts.

Table 5: Knowledge about Persistence of FGM of women's of Damot Gale Woreda, Wolayita Zone, Southern Ethiopia 2018. 


\begin{tabular}{|c|c|c|}
\hline Characteristics & Participants & Frequency \\
\hline \multicolumn{3}{|c|}{ Heard messages on existence of FGM } \\
\hline Yes & 300 & 90.1 \\
\hline No & 33 & 9.9 \\
\hline \multicolumn{3}{|c|}{ Sources of information about FGM } \\
\hline Radio & 121 & 36.3 \\
\hline Religion leader & 19 & 5.7 \\
\hline Community conversation & 81 & 24.3 \\
\hline Educated children & 6 & 1.8 \\
\hline Anti-FGM committee & 11 & 3.3 \\
\hline Health extension & 61 & 18.3 \\
\hline Women's affair & 1 & 0.3 \\
\hline \multicolumn{3}{|c|}{ Knowledge of circumcision as crime } \\
\hline yes & 250 & 75.1 \\
\hline No & 83 & 24.9 \\
\hline \multicolumn{3}{|c|}{ Do you know anyone who punished by FGM } \\
\hline Yes & 171 & 51.6 \\
\hline No & 161 & 48.3 \\
\hline \multicolumn{3}{|c|}{ Do you expose any action which promote FGM } \\
\hline \multicolumn{3}{|l|}{ Yes } \\
\hline \multirow[t]{2}{*}{ No } & 228 & 68.4 \\
\hline & 105 & 31.5 \\
\hline \multicolumn{3}{|l|}{ If no why } \\
\hline Fear of Social exclusion & 17 & 5.1 \\
\hline Good Tradition & 62 & 18.6 \\
\hline Lack of commitment & 11 & 3.3 \\
\hline I have no information & 12 & 3.6 \\
\hline Fear of religious leader & 3 & 0.9 \\
\hline
\end{tabular}




\begin{tabular}{|lll|} 
No & 228 & 68.5 \\
Weak implementation of law & 104 & 31.2 \\
Community resistance to anti-FGM activity & 135 & 58.2 \\
Other & 89 & 38.4 \\
& 8 & 3.4 \\
\hline
\end{tabular}

\section{Analysis of Factors Associated to Female Genital Mutilation}

\section{Bivariate Analysis}

Bivariate analysis revealed the following: maternal education (COR: $0.467,95$ percent $\mathrm{Cl}: 0.212,1.029$ ), age of daughters (COR 1.92, 95 percent Cl: $0.53,1.25$ ) house hold wealth index quintal (COR: $0.768,95$ percent Cl: 0.550, 1.072), father's educational status (COR: 1.135, 95 percent $\mathrm{Cl}: 0.808,1.595)$, good tradition (COR: 1.135, 95 (COR: 9.895, 95 percent Cl: 2.213, 4.251), At a p-value of 0.25, knowledge of FGM health complications (COR: 0.339, 95 percent Cl: 0.134, 0.859) and knowledge of FGM law (COR: $0.042,95$ percent $\mathrm{Cl}: 0.005,0.349)$ were candidate variables for a multivariate logistic regression model(Table6).

Table 6: Bivariate Analysis of Factors associated with FGM of women's of Damot Gale Woreda, Wolayita Zone, Southern Ethiopia 2018. 


\begin{tabular}{|c|c|c|c|c|}
\hline \multirow[t]{2}{*}{ Characteristics } & \multicolumn{2}{|l|}{ FGM } & \multirow[t]{2}{*}{$P$ value } & \multirow[t]{2}{*}{ COR } \\
\hline & Yes & No & & \\
\hline \multicolumn{5}{|c|}{ Maternal education } \\
\hline Literate & 121 & 36.3 & 1 & 1 \\
\hline Illiterate & 212 & 63.7 & 0.049 & 0.467 \\
\hline \multicolumn{5}{|c|}{ Age at circumcision } \\
\hline $1-5$ & 171 & & 0.0482 & 0.92 \\
\hline $6-10$ & 86 & & & \\
\hline $11-15$ & 34 & & & \\
\hline $16-20$ & 3 & & & \\
\hline$>21$ & 2 & & & \\
\hline \multicolumn{5}{|l|}{ Wealth quintile } \\
\hline Lower quintile & 66 & 19.8 & & \\
\hline Second quintile & 67 & 20.2 & 0.121 & 0.768 \\
\hline Middle quintile & 66 & 19.8 & & \\
\hline Fourth quintile & 67 & 20.2 & & \\
\hline Highest quintile & 66 & 19.8 & & \\
\hline \multicolumn{5}{|c|}{ Husband Education } \\
\hline Educated & 143 & 42. & 1 & 1 \\
\hline No education & 190 & 57.1 & 0.165 & 1.135 \\
\hline \multicolumn{5}{|l|}{ Good tradition } \\
\hline Yes & 152 & 45.6 & 1 & 1 \\
\hline No & 180 & 54.4 & 0.003 & 9.895 \\
\hline \multicolumn{5}{|c|}{ Knew FGM cause health problems } \\
\hline Yes & 216 & 64.9 & 1 & 1 \\
\hline No & 116 & 34.8 & 0.023 & 0.339 \\
\hline \multicolumn{5}{|c|}{ Knowledge towards FGM law } \\
\hline Yes & 250 & 75.1 & 1 & 1 \\
\hline No & 81 & 24.3 & 0.103 & 0.042 \\
\hline
\end{tabular}




\section{Multivariate Analysis}

During crude analysis, factors were adjusted using multiple logistic regressions to predict variables related with Female Genital Mutilation. At a p-value of 0.05 , variables such as age, maternal education, traditional FGM, and knowledge of health complications connected to FGM were significant.

The odds of experiencing FGM were nearly 45 percent higher in mothers who did not educate than in mothers who did [AOR: $0.454,95 \% \mathrm{Cl}: 0.209,0.984]$. The odds of experiencing FGM were about two times higher in younger daughters than in elder daughters [AOR: $0.454,95 \% \mathrm{Cl}: 0.209,0.984$ ]. (AOR: $1.86 ; 95 \%$ $\mathrm{Cl}: 0.42,0.98)$. Women who accept FGM because of tradition have 14 times higher odds of performing it than women who oppose it [AOR: 14.595, 95\% Cl: 3.391, 6.807]. Moreover FGM in the house hold which mothers didn't know about the any of health complication of FGM were 35\% more at risk of performing FGM as compared to in the house hold in which mothers knows about the health complication of FGM [AOR: $0.356,95 \% \mathrm{Cl}: 0.145,0.877]$.(Table 7).

Table 7: Multivariate Analysis of factors associated with FGM of women's of Damot Gale Woreda, Wolayita Zone, Southern Ethiopia 2018. 


\begin{tabular}{|c|c|c|c|c|c|}
\hline \multirow[t]{2}{*}{ Characteristics } & \multicolumn{2}{|l|}{ FGM } & \multirow[t]{2}{*}{$P$ value } & \multirow[t]{2}{*}{ COR } & \multirow[t]{2}{*}{ AOR } \\
\hline & Yes & No & & & \\
\hline \multicolumn{6}{|c|}{ Maternal education } \\
\hline Literate & 121 & 36.3 & & 1 & 1 \\
\hline Illiterate & 212 & 63.7 & 0.045 & 0.467 & 0.454 \\
\hline \multicolumn{6}{|c|}{ Age at circumcision } \\
\hline $1-5$ & 171 & & 0.0423 & 1.92 & 1.86 \\
\hline $6-10$ & 86 & & & & \\
\hline $11-15$ & 34 & & & & \\
\hline $16-20$ & 3 & & & & \\
\hline $21-25$ & 1 & & & & \\
\hline$>25$ & 1 & & & & \\
\hline \multicolumn{6}{|l|}{ Good tradition } \\
\hline Yes & 152 & 45.6 & 0.000 & 9.895 & 14.595 \\
\hline No & 180 & 54.4 & & 1 & 1 \\
\hline \multicolumn{6}{|c|}{ Knew FGM cause health problems: } \\
\hline \multirow[t]{2}{*}{ No } & 216 & 64.9 & & 1 & 1 \\
\hline & 116 & 34.8 & 0.025 & 0.339 & 0.356 \\
\hline
\end{tabular}

\section{Discussion}

In Damot Gale Woreda, Wolayita Zone, and Southern Ethiopia, researchers looked into the incidence of female genital mutilation and the factors that contribute to it. FGM was found to be prevalent in $89 \%$ of the sample population, and it was closely linked to age, maternal education, traditional support, and a lack of information about the health consequences. Despite many interventions in Damote Gale Woreda and Wolaita Zone, the practice of female genital mutilation (FGM) has remained. implying that the practice is still going on even if there is access to appropriate health information (Demographic and health survey, 2016).

The prevalence was lower than that of a research conducted in Ethiopia's East Gojjam Zone, Amhara Region, in 2012, which found a prevalence of 62.7 percent (8). When compared to EDHS in the same region report with prevalence of $(71 \%)$ and lower than the same area, the present value is greater $(92.3 \%)$ 
(Demographic and health survey, 2016). In comparison to a community-based survey done in Kersa district, Eastern Hararge Zone, the current finding was lower (93\% )(Yirga et al., 2012).

FGM was found to be 87.1 percent $(10 \%)$ in a cross-sectional survey done in Somali refugees in eastern Ethiopia in 2017, which is lower than this study. Also, a study conducted on the Bale zone of Ethiopia and the Pusiga District of northern Ghana found prevalence rates of 78.5 percent and 61 percent, respectively, which is lower than our findings. This could be due to differences in study locations and socioeconomic status.(Bogale, Markos and Kaso, 2014)(Sakeah et al., 2018).

This study found that education changed people's minds on the practice of female genital mutilation. This study found that when people's educational levels rise, they are less likely to endorse the practice of female genital mutilation (FGM). That is, the more educated people are, the more they reject the continuance of FGM ( 64 percent and 36 percent rejection of FGM by those with formal education and those with no education, respectively), which is similar with findings from other studies (Andualem, 2016; Gajaa et al., 2016; Fite et al., 2020). FGM was more common in households where the mothers were uneducated than in those where the mothers were educated. Getting an education preserves women's lives by roughly 45 percent compared to those who do not. Similarly, a mother's educational level appears to have a significant impact on a daughter's likelihood of being circumcised; 56 percent of daughters of moms with no formal education are circumcised, compared to 26 percent of daughters of women with at least some secondary education.(UNICEF, 2013a).

Similar studies on characteristics linked with perceived continuation of Female Genital Mutilation Ethiopia in terms of education status found that individuals with a primary education were 0.65 times less likely to favor the continuation of FGM than those with no formal education level... Similarly, those with higher education level were 0.14 times less likely to support for the continuation of the practice than those with no formal education (Fikrie, 2011). The findings contradict those of a study conducted in eastern Hararge, which found no link between parental education and FGM (Andualem, 2016). This could be explained by the expectation that women with higher education would have more access to and exposure to media and advocacy messaging, as well as a stronger understanding of the human rights implications.

Another important factor was age; the magnitude of Female Genital Mutilation in this study area was significantly associated with age, with magnitude decreasing as age increased. This could be due to the fact that as daughters grow older, their thinking matures and they can identify what is best for their future lives, so they may refuse circumcision. Result shows the odds of experiencing FGM were about two times more in younger daughters than older daughter (AOR-1.86,95\% $\mathrm{Cl} ; 0.42,0.98$ ). This result was in the same line with the research done in Bale Ethiopia (Bogale, Markos and Kaso, 2014).But this result was in opposite to the result of the study which was conducted in Afar, Ethiopia that shows being higher age had an association to the prevalence of female Genital Mutilation at the study area (AOR, 11.56; $95 \% \mathrm{Cl}: 2.56,48.39)$ and also similar result was seen in a research at Bawku municipality and Pusiga District of northern Ghana with result of (AOR: 4.24; 95\% Cl: 2.62-6.85) (Sakeah et al., 2018)(Abeya, 
Chuluko and Gemeda, 2017)(Karmaker et al., 2011). This variation with the current finding was due to inhabitants are from a different country which could have a different socio cultural differences. And According to Ethiopian Demographic and Health Survey circumcised women at the age category of 1549 nearly half of women $(49 \%)$ reported that they were circumcised when they were younger than age 5 , $22 \%$ between ages $5-9,18 \%$ between ages $10-14$, and $6 \%$ at age 15 or older (Demographic and health survey, 2016) this shows that prevalence decrease with the age.

The determining factor on the prevalence of FGM in this research was knowledge about the health problems of FGM. Moreover FGM in the house hold which mothers didn't know about the any of health complication of FGM were 65\% more at risk of performing FGM as compared to in the house hold in which mothers knows about the health complication of FGM , Which is same percent as research finding done on school girls in Addis Ababa factors associated with perceived continuation of Female Genital Mutilation showed that those who have knowledge of avoiding HIV/AIDS was $60 \%($ Fikrie, 2011). Knowledge of women's in this study was four major complication areas such as excessive bleeding (22.2\%), obstructed labor (21.9\%), menstrual disturbance (17.4\%) and sexual problems (25.5\%). Similar study which is done at Gambia indicates that, higher prevalence of long-term health problems such as dysmenorrhea, vaginal pain problems related to anomalous healing such as keloid and sexual dysfunction. Women with FGM/C were also much more likely to suffer complications during delivery for example, perineal tear, obstructed labor, and episiotomy(Kaplan et al., 2013). Other complications secondary to FGM according to the study conducted at Bale zone Ethiopia adds excessive bleeding at the time of the procedure, infection, urine retention and swelling of genital organ(Bogale, Markos and Kaso, 2014)( $\mathrm{H}$ et al., 2017).

The main other reason in this study for the higher prevalence of FGM in this study is that the perception of community members about FGM practice as a tradition. The long persistence of FGM is partly ascribed to the dominant role of men played in influencing the society as a whole. In which majority of participants claimed a tradition was the main reason for a long term persistence of FGM in this study area supported due to good tradition FGM shows that women's who was support FGM as a good tradition was 14 times more likely circumcised than women's who oppose the practice. Which is also supported by a community-based cross-sectional survey was conducted in Kersa district Eastern Hararge in which societal beliefs played a major role from this was the main reason given for Genital Cutting was to reduce "female hyperactivity" in sexual practice, and was the response of $60 \%$ of the women, while a quarter of the women responded that it was done to prevent early initiation of sexual activity (Yirga et al., 2012).

\section{Conclusion}

This study was set up to assess the level of Female Genital Mutilation and associated factors among women's of Demote Gale Woreda, Wolayita zone, Southern Ethiopia. The results of the present study revealed that the practice of FGM is widespread among the Demote Gale Woreda community, and there was a considerable support for the continuation of the practice. Based on the finding Female Genital 
Mutilation was commonly practiced by most respondents even though it was the major health and human rights issue. FGM could be decreased by interventions aimed to educate mothers and increase awareness about FGM.

Therefore, extension education should be strengthened and should provide comprehensive, accurate and timely information on the consequence of female genital mutilation. An integrated effort between Woreda administrative and the surrounding community need to be initiated to alleviate FGM practices through empowering women, discouraging risky factors like traditions and religion based traditions that push them to engaged to FGM; and sensitizing parents, community members and the public focusing on the rejecting of FGM.

\section{STRENGTH AND LIMITATION OF THE STUDY}

The strength of this study is being a community based study and large sample size. The limitation of the study is due to cross-sectional it cannot measure cause effect relationship and that the study relied on participants' self-reported data, which was prone to social desirability bias due custom and tradition influence on FGM. But, close monitoring by supervisor and principal investigator was made to minimize such biases, clarification of potential ambiguities and misunderstandings, maintaining privacy of participants and proving for answers were carried out by interviewers.

\section{Declarations}

Acknowledgment: we would like to say thank you very much for all Parents who are involved as study participant in this study.

Consent to publish: Not applicable.

Availability of data and materials: For those who are interested the datasets analyzed during the current study are available from the corresponding author on reasonable request.

Competing interests: The authors declare that they have no competing interests.

\section{Ethics Approval and Consent to Participate}

The study was conducted after getting approval from Hawassa University institutional review board (IRB) to conduct the study. A formal support letter was written to Damot Gale Woreda administrative office and the Woreda wrote the official letter to the sampled Kebeles and concerned offices, where the study conducted. Both verbal and written informed consents were obtained from the study participants. For those who are unable to read and write verbal consent were obtained after explaining the purpose of the study while for those who are able to write and read, written consent were obtained. During the consent process first IRB-approved version of consent form in Amharic (the local language) language prepared. All participants were assured that their name will not be stated, data will be kept confidential and anonymous and it will be used only for research purpose. 
Funding: Not applicable

Authors Contribution: $\mathrm{BB}, \mathrm{AF}$, conceived and designed the study and developed the data collection instruments. BB and AF performed the statistical analysis and wrote all versions of the manuscript. All authors critically revised and approved the final manuscript.

\section{Competing interests}

The authors declare that they have no competing interests

\section{Abbreviations}

AIDS: Acquired Immunodeficiency Diseases; AOR: Adjusted Odd Ratio; Cl: Confidence Interval; COR: Crude Odd Ratio; EDHS :Ethiopia Demographic Health Survey; FGM: Female Genital Mutilation; SNNPR: Southern Nation Nationality Peoples Region; SPSS: Statistical Package for Social Science Students; TBA :Traditional Birth Attendants ;UNICEF: United Nation International Child Ethiopia Fund; USAID: United State Agency International for Development ;UNFPA: United Nation Population Fund; WHO :World Health Organization

\section{References}

Abeya, S. G., Chuluko, B. G. and Gemeda, D. D. (2017) 'Factors associated with female genital mutilation among women of reproductive age in Gewane Woreda, Afar national egional state, Ethiopia', Remedy Open Access, 2, pp. 1-5.

Bogale, D., Markos, D. and Kaso, M. (2014) 'Prevalence of female genital mutilation and its effect on women's health in Bale zone, Ethiopia: A cross-sectional study', BMC Public Health, 14(1), pp. 1-10. doi: 10.1186/1471-2458-14-1076.

Demographic and health survey (2016).

Ethiopian Public Health Institute Addis Ababa (2019) 'Ethiopia Mini Demographic and Health Survey', FEDERAL DEMOCRATIC REPUBLIC OF ETHIOPIA Ethiopia.

European Institute for Gender Equality (2018) 'Female genital mutilation How many girls are at risk in France?', EIGE.

Andualem, M. (2016) 'Determinants of Female Genital Mutilation Practices in East Gojjam Zone, Western Amhara, Ethiopia', Ethiopian medical journal, 54(3), pp. 109-116.

Fite, R. O. et al. (2020) 'Prevalence of female genital mutilation among women in Ethiopia: A systematic review and meta-analysis', Heliyon. Elsevier Ltd, 6(7), p. e04403. doi: 10.1016/j.heliyon.2020.e04403. 
Gajaa, M. et al. (2016) 'Prevalence and associated factors of circumcision among daughters of reproductive aged women in the Hababo Guduru District, Western Ethiopia: A cross-sectional study', BMC Women's Health. BMC Women's Health, 16(1), pp. 1-9. doi: 10.1186/s12905-016-0322-6.

Fikrie, Z. (2011) 'Factors associated with perceived continuation of females' genital mutilation among women in Ethiopia', Ethiopian Journal of Health Sciences, 20(1), pp. 49-53. doi:

10.4314/ejhs.v20i1.69425.

H, D. et al. (2017) 'Prevalence of Female Genital Mutilation and its Association with Birth Complications among Women Attending Delivery Service in Nigist Eleni Mohammed General Hospital, Hossana, Southern Nations, Nationalities and Peoples' Region, Ethiopia', Reproductive System \& Sexual Disorders, 06(04). doi: 10.4172/2161-038x.1000214.

Kaplan, A. et al. (2013) 'Female genital mutilation/cutting in The Gambia: Long-term health consequences and complications during delivery and for the newborn', International Journal of Women's Health, 5(1), pp. 323-331. doi: 10.2147/IJWH.S42064.

Karmaker, B. et al. (2011) 'Factors associated with female genital mutilation in Burkina Faso and its policy implications', International Journal for Equity in Health, 10, pp. 1-9. doi: 10.1186/1475-9276-1020.

Odukogbe, A. T. A. et al. (2017) 'Female genital mutilation/cutting in Africa', Translational Andrology and Urology, 6(2), pp. 138-148. doi: 10.21037/tau.2016.12.01.

Sakeah, E. et al. (2018) 'Prevalence and factors associated with female genital mutilation among women of reproductive age in the Bawku municipality and Pusiga District of northern Ghana 11 Medical and Health Sciences 1117 Public Health and Health Services', BMC Women's Health, 18(1), pp. 1-10. doi: 10.1186/s12905-018-0643-8.

The European Institute for Gender Equality (2015) Estimation of girls at risk of female genital mutilation in the European Union Report.

UNFPA-UNICEF (2019) 'Beyond the crossing FEMALE GENITAL MUTILATION', UNFPA, (Report).

UNICEF (2013a) Female Genital Mutilation/Cutting: a statistical overview and exploration of the dynamics of change, Reproductive Health Matters. doi: 10.1016/s0968-8080(13)42747-7.

WHO fact sheet, 2019 (2019) 'Female genital mutilation', Clinical Risk, 14(5), pp. 189-192. doi: $10.1258 /$ cr.2008.080056.

WHO, P. (2016) 'Understanding and addressing violence against women Female genital mutilation', World Health Organization, 1(December), pp. 1-8. 
Yirga, W. S. et al. (2012) 'Female genital mutilation: Prevalence, perceptions and effect on women's health in Kersa district of Ethiopia', International Journal of Women's Health, 4(1), pp. 45-54. doi: 10.2147/IJWH.S28805.

\section{Figures}

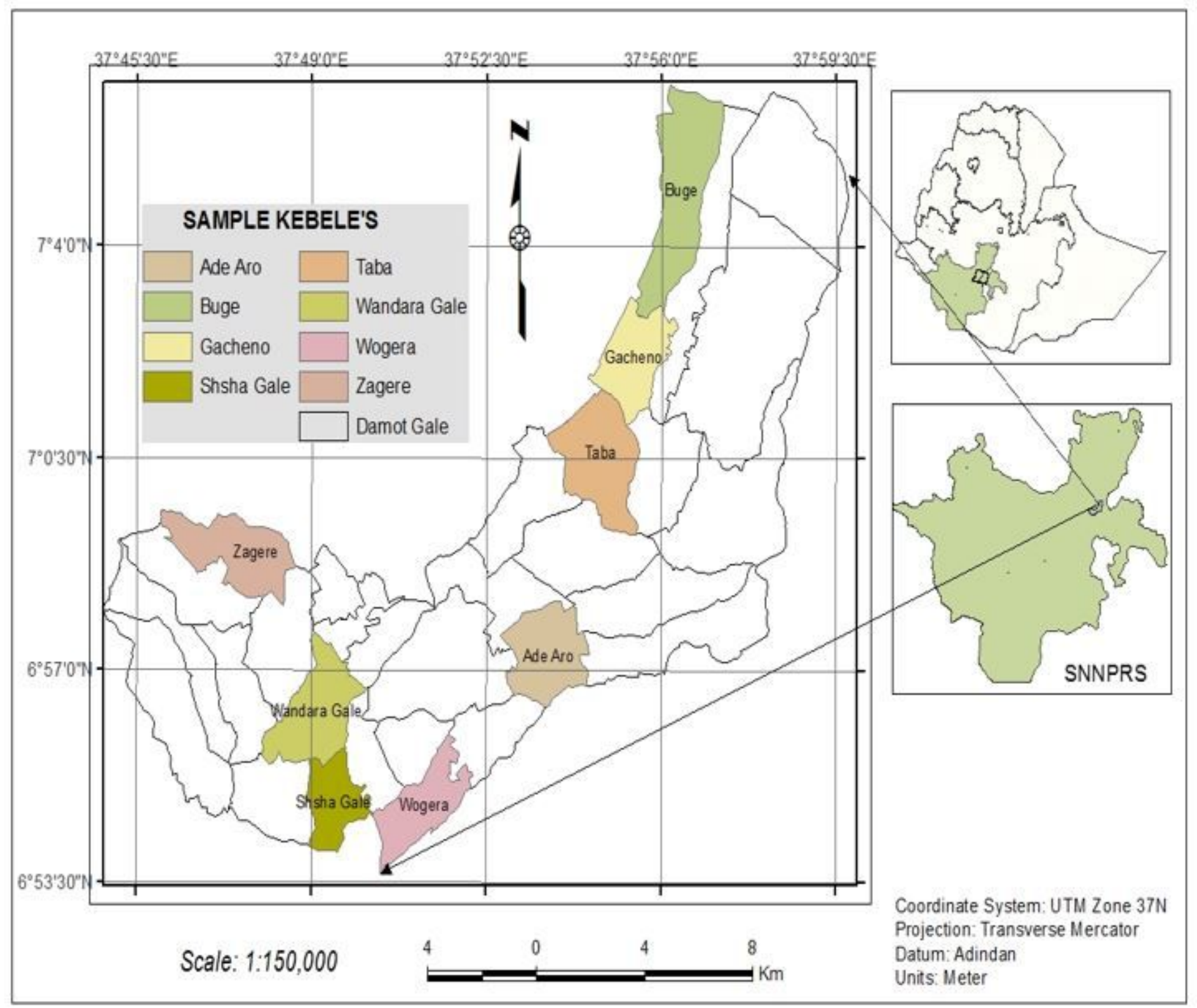

\section{Figure 1}

The Map of study area (source; Ethiopian GIS and RS team WWDSE, 2013) 


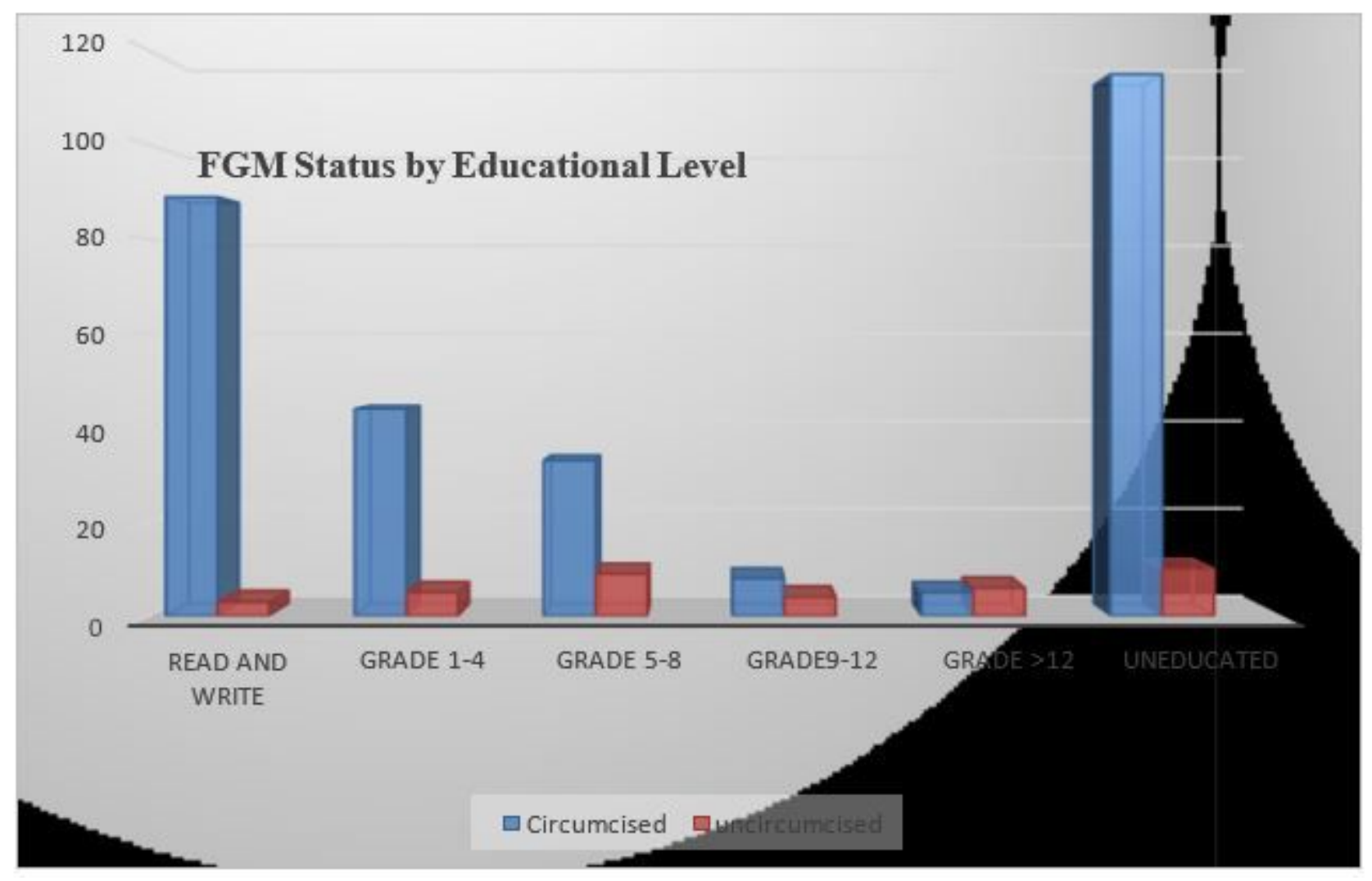

Figure 2

Circumcision statuses by educational level

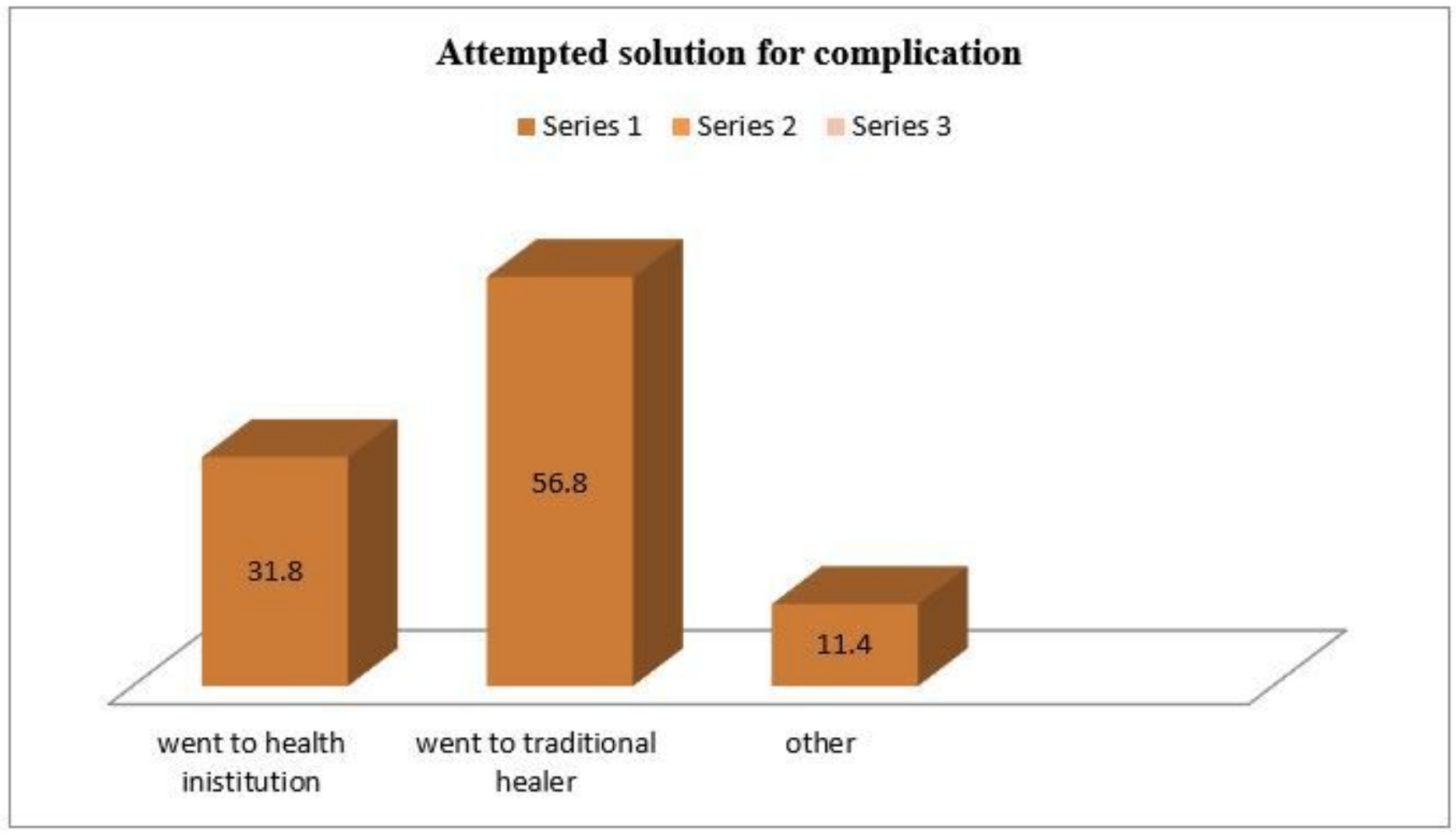

Figure 3 
Attempted solutions for health complications

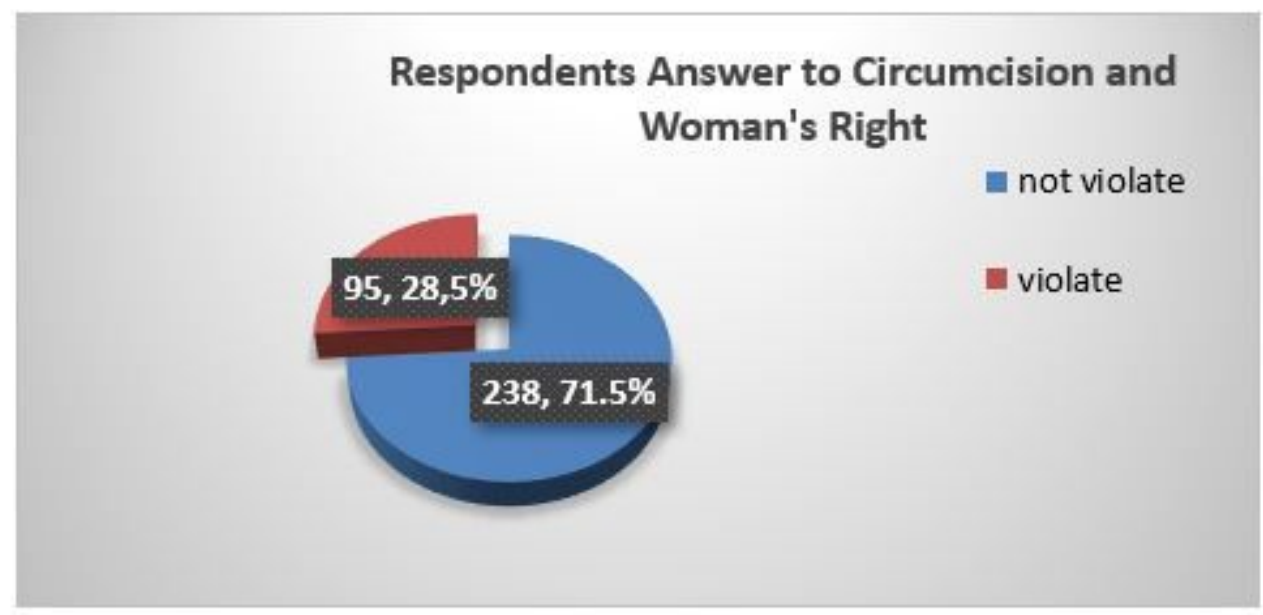

Figure 4

Respondents thought about FGM law 